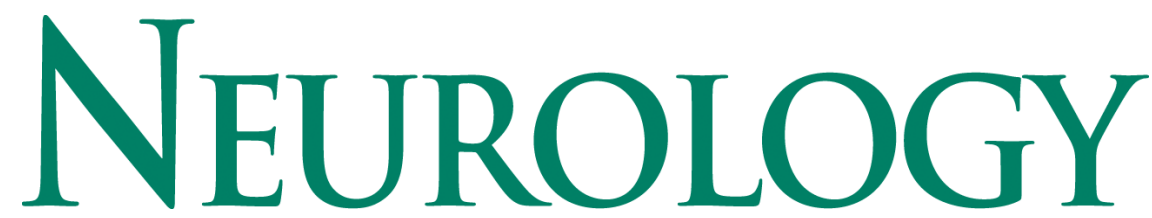

USE OF STATINS AND INCIDENCE OF DEMENTIA AND COGNITIVE IMPAIRMENT WITHOUT DEMENTIA IN A COHORT STUDY

Mark R. Goldstein, Luca Mascitelli, Francesca Pezzetta, M.N. Haan, C. Cramer, J.

Kalbfleisch, K. Langa and S. Galea

Neurology 2009;72;1190-1191

DOI: 10.1212/01.wnl.0000346461.00520.28

This information is current as of April 6, 2009

The online version of this article, along with updated information and services, is located on the World Wide Web at:

http://www.neurology.org/cgi/content/full/72/13/1190

Neurology ${ }^{\circledR}$ is the official journal of the American Academy of Neurology. Published continuously since 1951, it is now a weekly with 48 issues per year. Copyright () 2009 by AAN Enterprises, Inc. All rights reserved. Print ISSN: 0028-3878. Online ISSN: 1526-632X.

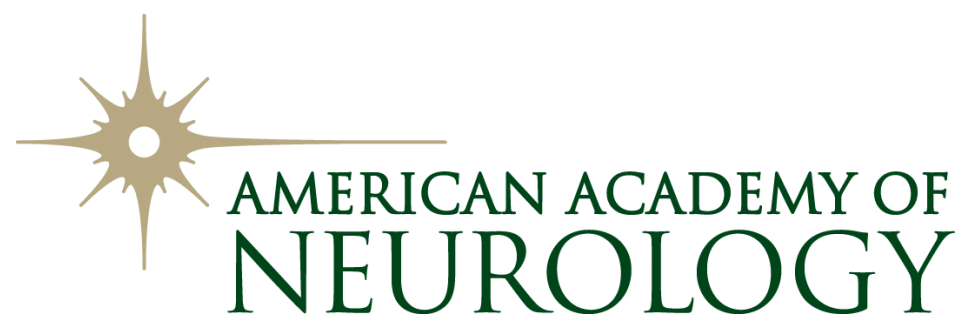


Finally, we agree with Dr. Hussain et al. on the potential insensitivity of the instrument used for the screening of depression. To gauge a better understanding of depressive symptoms in children and adolescents with MS, we have included a psychiatric interview in the ongoing follow-up evaluation of our cohort.

M.P. Amato, B. Goretti, A. Ghezzi, S. Lori, V. Zipoli, E. Portaccio, L. Moiola, M. Falautano, M.F. De Caro, M. Lopez, F. Patti, R. Vecchio, C. Pozzilli, V. Bianchi, M. Roscio, G. Comi, M. Trojano, for the MS Study Group of the Italian Neurological Society, Florence, Italy

Disclosure: The study to which this correspondence refers was supported in part by a grant from Biogen-Dompè.

Copyright (c) 2009 by AAN Enterprises, Inc.

1. Amato MP, Goretti B, Ghezzi A, et al. Cognitive and psychosocial features of childhood and juvenile MS. Neurology 2008;70:1891-1897.

2. Sadovnick AD, Remick RA, Allen J, et al. Depression and multiple sclerosis. Neurology 1996;46:628-632.

3. Beiske AG, Svensson E, Sandanger I, et al. Depression and anxiety amongst multiple sclerosis patients. Eur J Neurol 2008;15:239-225.

\section{USE OF STATINS AND INCIDENCE OF DEMENTIA AND COGNITIVE IMPAIRMENT WITHOUT DEMENTIA IN A COHORT STUDY}

To the Editor: We read the interesting observational study of Cramer et al. ${ }^{1}$ regarding statin therapy and the incidence of cognitive impairment without dementia and dementia in an elderly MexicanAmerican population. The authors conclude that statin users are half as likely to develop cognitive impairment or dementia over the 5 years of observation. However, the study suggests that higher cholesterol levels actually protect subjects from cognitive impairment and dementia.

Baseline total cholesterol levels of statin-treated populations are higher than those of the general population. ${ }^{2}$ Presumably, the cholesterol levels of the statin-treated patients in this study were higher than those of the non-statin treated patients. In the Framingham Heart Study cohort, subjects with total cholesterol levels more than $200 \mathrm{mg} / \mathrm{dL}$, compared to those with levels less than $200 \mathrm{mg} / \mathrm{dL}$, performed significantly better in cognitive measures including word fluency, attention, and concentration. The observation period in that study predated the widespread use of statins. ${ }^{3}$

Moreover, an 8-year observational trial involving middle-aged women revealed that women with higher low-density lipoprotein (LDL) cholesterol levels had a significantly better memory. ${ }^{4}$ Interest- ingly, Cramer et al. found that baseline modified Mini-Mental State Examination scores were significantly higher in statin users compared to statin nonusers, suggesting a benefit from higher cholesterol levels.

Both lipophilic and hydrophilic statins promote oligodendrocyte lineage commitment by parenchymal glial progenitor cells in vitro. ${ }^{5}$ If statins are taken for decades, it is possible that the homeostatic selfrenewal of glial progenitor cells may be impaired, resulting in cognitive decline. Therefore, statins may be detrimental over the long term by both lowering cholesterol levels and diminishing the glial progenitor cell pool.

Finally, we need long-term randomized prospective trials specifically designed to settle this important dispute. Regarding cholesterol and cognitive decline, perhaps more is better.

Mark R. Goldstein, MD, Bonita Springs, FL;

Luca Mascitelli, MD, Udine, Italy;

Francesca Pezzetta, MD, Tolmezzo, Italy

Disclosure: The authors report no disclosures.

Reply from the Authors: The Goldstein et al. letter highlights the importance of considering adverse effects from overly effective lipid lowering drugs.

Some studies have found a decline in cholesterol levels in older populations associated with adverse outcomes. Interpretation of decline is not straightforward. Curb et al. ${ }^{6}$ found a u-shaped association between coronary heart disease outcomes and concluded that LDLlowering drugs could still be used in older populations with the caveat that statins have the potential to lower LDL-C too far. Reasons for declines of cholesterol in old age may be multivariate (e.g., weight loss, reduction in muscle mass) and may be unrelated to statin use. LDL declines may be markers of prodromal changes accompanied by cognitive decline.

Baseline LDL-C levels in our population were higher in nonstatin vs statin users: 123 vs $112 \mathrm{mg} /$ $\mathrm{dL}$, respectively $(p=0.0002)$. Total cholesterol was 212 vs 204 ( $p=0.016)$. LDL in statin users declined over time more rapidly than in nonstatin users. We found that higher LDL-C over time is associated with higher mortality rates (Cox model $=\mathrm{HR}: 1.89$ for a LDL-C SD of 34.5, $p=0.02$ ), which may indicate a direct effect of LDL-C or the residual association of LDL with heart disease. Change in LDL-C over time is not associated with dementia/CIND incidence. LDL-C does modify the effect of statin use on dementia/CIND. A one SD decrease in LDL-C $(34.5 \mathrm{mg} / \mathrm{dL})$ is associated with an approximately $54 \%$ increase in the benefit associated with statin use (HR for statin use: $0.29, p=0.04$ for interaction between LDL and statins). 
Our results confirm that those who are taking statins over time may experience lower rates of cognitive impairment and dementia related to the reduction in LDL-C. This result does not support a treatment recommendation.

We would enthusiastically support a primary prevention trial that could examine the effects of lowering lipids on the development of incident dementia and $\mathrm{AD}$. However, a primary prevention trial should be preceded by a better understanding of the mechanisms by which statins may confer this benefit and should include arms for both behavioral and various drug treatments.

M.N. Haan, C. Cramer, J. Kalbfleisch, K. Langa,

S. Galea, Ann Arbor, MI

Disclosure: Caryn Cramer was employed by Pfizer Corporation during completion of her doctoral degree during which time this study was conducted. Pfizer did not provide any material support for this study, and did not participate in the design, conduct, management, analysis, interpretation, review, or approval of the study or the manuscript. The other authors have reported no disclosures.

Copyright () 2009 by AAN Enterprises, Inc.

1. Cramer C, Haan MN, Galea S, et al. Use of statins and incidence of dementia and cognitive impairment without dementia in a cohort study. Neurology 2008;71:344-350.

2. Thompson R, O'Regan C, Morant S, et al. Measurement of baseline total cholesterol: new data from The Health Improvement Network (THIN) database. Prim Care Cardiovasc J 2008;1:107-111.

3. Elias PK, Elias MF, D'Agostino RB, et al. Serum cholesterol and cognitive performance in the Framingham Heart Study. Psychosom Med 2005;67:24-30.

4. Henderson VW, Guthrie JR, Dennerstein L. Serum lipids and memory in a population based cohort of middle aged women. J Neurol Neurosurg Psychiatry 2003;74:1530 1535.

5. Sim FJ, Lang JK, Ali TA, et al. Statin treatment of adult human glial progenitors induces PPAR gamma-mediated oligodendrocytic differentiation. GLIA 2008;56:954962.

6. Curb JD, Abbott RD, Rodriguez BL, et al. Prospective association between low and high total and low-density lipoprotein cholesterol and coronary heart disease in elderly men. J Am Geriatr Soc 2004;52:1975-1980.

\section{STROKE: THE ELIXHAUSER INDEX FOR COMORBIDITY ADJUSTMENT OF IN-HOSPITAL CASE FATALITY}

To the Editor: I read with interest the article by Zhu et al. ${ }^{1}$ However, I did not see that any screening for dysphagia or aspiration pneumonia was made. If this search was made, it is possible that the population was excluded.

If this screening was not done and this was added using ICD (9 or 10) search terms for dysphagia (787.20) or aspiration pneumonia (507.0), what impact this would have on inpatient fatality? Most stroke patients who aspirate and get pneumonia have a prolonged length of stay and increased morbidity and mortality compared to those who have stroke but do not have pneumonia.

The Stroke Centers by Joint Commission in the United States are required to document dysphagia screening to gauge aspiration risk.

William D. Freeman, Jacksonville, FL

Disclosure: The author reports no disclosures.

Reply from the Authors: We thank Dr. Freeman for his comments. We did not use codes for dysphagia or pneumonia to identify potential stroke patients. We believe that these codes would be relatively nonspecific but agree that using such codes would allow the identification of more strokes. Dr. Freeman's point illustrates why passive surveillance of stroke using administrative data is limited by the extent of the data definition.

We did not investigate whether, among stroke patients with dysphagia or with pneumonia as a comorbid code, there was a higher mortality or longer length of stay compared to those without such codes. We suspect that Dr. Freeman is correct.

In Canada, there is ongoing work spearheaded by the Canadian Stroke Network and the Heart \& Stroke Foundation of Canada to include elements of stroke care (e.g., dysphagia screening) in hospital accreditation. Similar to the Joint Commission in the United States, we soon hope to have similar accreditation standards for stroke hospitals and indicators such as dysphagia and aspiration screening will be routinely reported.

Michael D. Hill, Hai Feng Zhu, Calgary, Canada

Disclosure: The authors report no disclosures.

Copyright () 2009 by AAN Enterprises, Inc.

1. Zhu H, Hill MD. Stroke: The Elixhauser Index for comorbidity adjustment of in-hospital case fatality. Neurology 2008;71:283-287.

\section{ETHICS OF PLACEBO-CONTROLLED CLINICAL TRIALS IN MULTIPLE SCLEROSIS: A REASSESSMENT}

To the Editor: Dr. Polman et al. ${ }^{1}$ cogently discussed the ethics of performing placebo-controlled trials in multiple sclerosis (MS). As part of their presentation, they discussed active comparator studies in which the medication to be evaluated is compared to an established effective therapy (EET). They did not support such studies being performed.

The authors note that of the two types of active comparator studies, noninferiority studies provide no assessment of absolute safety and should be considered unethical, and that superiority study designs are problematic or ethically questionable. I disagree and argue that rather than considering placebo- 
USE OF STATINS AND INCIDENCE OF DEMENTIA AND COGNITIVE
IMPAIRMENT WITHOUT DEMENTIA IN A COHORT STUDY

Mark R. Goldstein, Luca Mascitelli, Francesca Pezzetta, M.N. Haan, C. Cramer, J.

Kalbfleisch, K. Langa and S. Galea

Neurology 2009;72;1190-1191

DOI: 10.1212/01.wnl.0000346461.00520.28

This information is current as of April 6, 2009

\begin{tabular}{|ll|}
\hline $\begin{array}{l}\text { Updated Information } \\
\text { \& Services }\end{array}$ & including high-resolution figures, can be found at: \\
Pttp://www.neurology.org/cgi/content/full/72/13/1190 \\
Permissions \& Licensing & $\begin{array}{l}\text { Information about reproducing this article in parts (figures, tables) } \\
\text { or in its entirety can be found online at: } \\
\text { http://www.neurology.org/misc/Permissions.shtml }\end{array}$ \\
& $\begin{array}{l}\text { Information about ordering reprints can be found online: } \\
\text { http://www.neurology.org/misc/reprints.shtml }\end{array}$
\end{tabular}

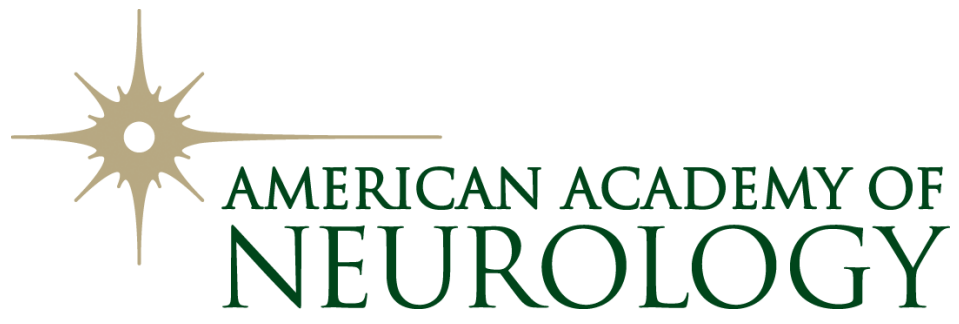

